Citation: Strugielska, A., \& Piątkowska, K. (2018). Towards a unified, socio-cognitive approach to languagemediated intercultural competence. Cognitive Studies / Études cognitives, 2018(18). https://doi.org/10.11649/ cs. 1523

\author{
ARIADNA STRUGIELSKA ${ }^{A} \&$ KATARZYNA PIĄTKOWSKA ${ }^{B}$ \\ Nicolaus Copernicus University, Toruń, Poland \\ $A$ ariadnas@umk.pl ; $B_{\text {kapia@umk.pl }}$
}

\title{
TOWARDS A UNIFIED, SOCIO-COGNITIVE APPROACH TO LANGUAGE-MEDIATED INTERCULTURAL COMPETENCE
}

\begin{abstract}
Very few intercultural competence (IC) models include language, and those that do so portray the notion in an inconsonant manner. Nonetheless, research shows that language assures successful intercultural communication. Thus, this article stresses the need for a unified socio-cognitive approach which will introduce common and solid foundations for the role and nature of both language and IC. The article demonstrates that such an integrated framework, built on a reappraised notion of language, helps to overcome numerous dichotomies within IC models and leads to the emergence of a unified approach to language-mediated IC.

Keywords: socio-cognitive approach; language; intercultural competence models
\end{abstract}

\section{Introduction}

Despite the existence of a link between language and IC, the two concepts have developed separately (Fantini, 2010, p. 263), with the result that the positioning of language and its facets (i.e. the language faculty, the linguistic system, and linguistic competence and performance) in the intercultural paradigm is not clearly defined and researchers disagree on whether or not they play any role in IC (Bennett, 1997). While recent studies (Fantini, 2010) have revealed that language facilitates the development of IC, few IC models include a consistent, if any, perspective on language. To be more precise, although certain dimensions, such as culture, competence, cognition, knowledge, skills or attitudes, are common to all IC models (Byram, 1997, 2006, 2012; Risager, 2004, 2006, 2007; Kramsch, 1993, 2015; Matsuo, 2014), the very notion of IC is conceptualised as an intangible phenomenon comprising a number of components interacting in a nonlinear way. IC can thus be defined as a complex system which, depending on the model adopted, reveals a set of dimensions assumed to facilitate intercultural communication. Consequently, Fantini (2010) calls 
for a new, coherent paradigm in intercultural research which will, above all, include language in a more comprehensive manner.

This article reconsiders the positioning of language in IC by exploring the potential contribution that a unified socio-cognitive approach, based on complexity science, cognitive psychology, grounded cognition, cognitive linguistics and intercultural pragmatics, can bring to establishing common foundations for language and IC. The paper is constructed as follows. Firstly, the nature and role of the facets of language (i.e. the language faculty, the linguistic system, and linguistic competence and performance) in IC models are discussed and the inconsistency in defining these notions is demonstrated. Specifically, it is argued that all IC models which include language lack a common denominator and emphasise the need for a more unifying model, built upon the premise of socio-cognitive linguistics, which will integrate language and IC in a holistic and coherent way. Such a model is proposed in the subsequent section and cognitive linguistics is viewed as the ultimate foundation for IC models.

\section{Language in IC models ${ }^{1}$}

As already signalled above, IC is a complex notion characterised by asymmetry in defining its dimensions, with emphasis fluctuating in an unbalanced way between culture, competence, cognition, knowledge, skills and attitudes, leading to unjustified dichotomies (see Strugielska \& Piątkowska, 2017 for details). Likewise, in their perspectives on language, researchers (Byram, 1997, 2006, 2012; Risager, 2004, 2006, 2007; Kramsch, 1993, 2015; Matsuo, 2014) oscillate between linguistic relativism and subject-positioning, between interactionism and symbolicity, between given and constructed meaning, between social aspects through individual and interactive experience, between language set in languacultural competence and language set in symbolic competence, between awareness and symbolic mentality, between language embedded in communication viewed as compositional and structural, and language embedded in communication viewed in a holistic way, between language set in the ability to communicate effectively and appropriately with people of various cultures, and language set in the ability to shape the context of its use. Thus, what would seem to be missing is an IC model that is able to reconcile the above incongruities as far as the facets of language are concerned, leading to facilitated intercultural communication based on IC as its integral aspect.

\section{The language faculty}

When discussing the language faculty, interculturalists mediate between the individual and the social, the cognitive and the constructivist, the static and the dynamic, the communicative and the symbolic, the compositional and the holistic.

From a cognitive mentalist perspective, which is reminiscent of the Chomskyan tradition, Byram $(1997,2006,2012)$ treats language as a separate element of IC, although he declares it inseparable from other components of IC (i.e. knowledge, skills and attitudes). Thus, language is treated as an autonomous faculty in the mind of the individual, which reveals a compositional perspective on its nature. Furthermore, from a mentalist perspective language expresses a particular worldview, determines our thought and shapes our perception of reality, which requires the development of the so called 'third space'. Accepting the Sapir-Whorf hypothesis of linguistic relativity, Byram's (1997) assumptions are in line with the idea of languages-cultures. Critical awareness, which relates to deeper cognition, skills and attitudes, and which enhances their development and derives from them at the same time, is a link between language and culture (Byram, 1997, 2006,

\footnotetext{
${ }^{1}$ The analysis of language in IC models may seem inconsistent due to the fact that the models themselves focus on language and its facets in a fragmentary and selective way.
} 
2012). Such a positioning of critical awareness in the model clearly places Byram (1997) within a cognitive perspective on the language faculty.

Risager (2004, 2006, 2007) considers the language faculty as a social construct. Based on five linguistic savoirs, Risager's languaculture model $(2004,2006,2007)$ complements Byram's perspective. Conceptualised from a cultural and social perspective, language is a central element of the model as it carries languaculture. Risager $(2004,2006,2007)$ embraces interface and noninterface positions with respect to the relationship between language and culture (despite her declaration that language is always cultural to some degree), i.e. she analyses language from a psychological and social perspective. From a psychological viewpoint, the focus is on identity between language and culture (i.e. they are manifestations of each other) as the two elements are unique to each individual and are part of their experience. Thus, this position is in line with a universalistic conception of a close bond between language, culture and mentality. However, despite the reference to an individual and universalistic perspective, language is not anchored in cognition in the languaculture model and a social aspect dominates the framework. From a social or linguistic viewpoint, language is seen as culturally neutral, or as an instrument for communication across cultures which are not territorially bound. In other words, language is an autonomous entity, which brings Risager close to Byram's position. Furthermore, the language faculty is grounded in linguistic resources (a cognitive element), which are some of the loci (linguistic practice and the linguistic system being the other loci) of the language faculty. The three loci are analysed from a cultural perspective which takes into consideration a generic and differential level of language and culture. On a generic level, language and culture are either psychological (cognitive) or social notions, yet language is always associated with culture and linguistic practice is placed within some cultural context. A differential level focuses on interface and non-interface between language and culture, as some aspects of culture are language-specific while others are not.

Similarly, Kramsch $(1993,2015)$ views the language faculty through a cognitive and social perspective. However, her linguaculture model is focused on symbolicity. This model assumes identity between language and culture. Following Byram's model, the linguaculture position includes criticality as an element linking language and culture but refers it to symbolic systems constructing culture. Therefore, language is seen in a situational context through interactive experience (a dynamic approach) set in symbolic competence, which is in opposition to Byram's approach. As a result of perceiving language as symbolic discourse, Kramsch (2011, p. 356) introduces the notion of a symbolic self, i.e. an interculturally competent individual constituted by "symbolic systems like language, as well as by systems of thought and their symbolic power". Thus, Kramsch oscillates between the cognitive and the social, accentuating the symbolic nature of language (re)constructed through interactive experience, which stands in contrast to Byram's emphasis on language as existing in the individual mind.

In Matsuo's (2014) approach language deepens the understanding of IC, which cannot be separated from language. The rationale behind this view is a supposition that "human existence, action, knowledge and ethics is linguistic" (Matsuo, 2014, p. 6). Language does not merely express our thought, but determines it.

\section{The linguistic system}

Rather than a code, language is viewed through a social perspective in IC models, where it is understood as discourse.

For Byram (1997) language is not a code. However, he does not define the notion, clearly marginalising the linguistic system. Risager $(2004,2006,2007)$ associates the linguistic system (which is one of the three loci of language) with language as a code, which, however, serves a prescriptive purpose. Kramsch (2011) views language primarily as a medium for communication rather than a code or a hermetic system. Consequently, language is defined as a symbolic system (discourse) constituted by a symbolic representation, action and power (Kramsch, 2011). As a symbolic repre- 
sentation, language reveals the mind as it refers to the way reality is rendered through lexis and grammatical structures, understood as conceptual categories, and idealised cognitive models referring to prototypes and stereotypes. Thus, viewing language through a conceptual and structural system, Kramsch makes reference to structural and cognitive linguistics. Language as symbolic action relates to intentions encoded in speech acts, speech genres, facework strategies and symbolic interaction rituals, which point to the understanding of language from a performative and functional perspective. Language as symbolic power reveals social relations reflected in intertextual relations, which emphasise the role of critical sociolinguistics in the perception of language. Consequently, in Kramsch's model language is discussed as discourse, which is defined as language use that goes beyond the code. Thus, she discards the view of discourse as structural units of language. Instead, Kramsch (2011, p. 356) suggests analysing discourse as offering "various ways of making meaning through various symbolic systems". Consequently, meaning is contextual and negotiated as it is constructed in interaction. It does not exist in language prior to interaction, and the role of language is to symbolically mediate meaning, structure individuals' conceptual systems and to be structured by them.

Referring to Kramsch and Bakhtin, Matsuo (2014) focuses on language as discourse whose basic unit of speech communication is the dialogic utterance in which words are signs. In fact, language is dialogue. Language is "an aggregate of speech genres, i.e. recurring social combinations of words" (Matsuo, 2014, p. 12) with discourse treated as the relationship between the speech genres. Words are subject to centripetal and centrifugal forces which are the sources of change in language. Consequently, Matsuo's (2014) view of language is close to a Vygotskian perspective, in which social aspects dominate. They constitute "the forces that create grammar" (Matsuo, 2014, p. 6). The importance of language as a social medium is also accentuated in the rejection of individualism (i.e. locating linguistic competence in the individual) introduced by Byram (1997). Language is the basis of communication, not a closed system.

\section{$5 \quad$ Linguistic competence}

Linguistic competence is marginalised in IC models, which is reflected in the fact that only two models include it.

Set in communicative competence, linguistic competence, along with sociolinguistic, discourse and intercultural competences, is recognised as one of the stable faculties of the mind in Byram's model (1997). Linguistic competence is mapped onto IC but the link between the two types of competence is not specified. Thus, placing linguistic competence outside other competences reveals a compositional perspective. The role linguistic competence plays in interaction is declared to be essential (Byram, 1997) but it is rather marginalised (IC and its components are of primary importance) or not even included in Byram's 2012 model. Furthermore, linguistic competence is analysed on a general level and its components are not specified.

A similar view is expressed by Risager $(2004,2006,2007)$. She includes ethnographic proficiency (an equivalent of Byram's savoir faire), which relates to the ability to examine the complexity of language through critical language awareness (an extension of Byram's critical cultural awareness) understood as perception of differences between first and second languages. Nonetheless, under the premise of the languaculture position, the nature, role and extent of critical language awareness is not specified.

\section{Linguistic performance}

Intercultural discourse is permeated with dichotomies with reference to linguistic performance as researchers oscillate between a compositional and a holistic nature of the notion, as well as the focus on the ability to communicate effectively and appropriately with people of various cultures and the ability to shape the context in which language is used. 
Byram (1997) equates linguistic performance with interaction. The model can be traced back to Hymes but redefines his notion of communicative competence. Rather than an exchange of ideas, communication in Byram's framework (1997) is viewed as an intercultural dialogue, i.e. action in the world. A key component of interaction is social identity, which determines such sociolinguistic functions as the speaker's ability to know when to speak, and what to speak about. A failure to identify the speaker's role or the context of communication may lead to a failure in interaction. In his model based on five savoirs, Byram (2006) introduces two types of skills (skills of discovery and interaction and skills of interpreting and relating) which refer to interaction. The skills of discovery and interaction involve "the ability to operate knowledge, attitudes and skills under the constraints of real-time communication and interaction", whereas the skills of interpreting and relating entail "the ability to interpret a document or event from another culture, to explain and to relate it to documents and events from one's own" (Byram, 2006, p. 11). However, despite the importance assigned to interaction in developing IC, linguistic competence is included as a separate element in the framework.

Putting an emphasis on language, Risager (2007) extends Byram's (1997) notion of five savoirs, four of which relate to linguistic performance, and applies them to language. Sociolinguistic competence is understood as a number of languacultural competences which include the ability to interpret a text dialogically, negotiate meaning, distinguish between semantic and pragmatic aspects (these competences enable the speaker to communicate interculturally), and to use language creatively and poetically. Discourse competence, which entails languacultural translation and interpretation, refers to the ability to interpret discourse and mediate meaning in cross-cultural situations. Transnational cooperation involves the ability to collaborate with institutions which enable the individual to construct their knowledge of the world and to interact with users of other languages. Thus, for Risager $(2004,2006,2007)$ linguistic practice is one of the loci of language.

According to Kramsch's linguacultural position (2011), linguistic performance is executed through intercultural (symbolic) competence (juxtaposed with communicative competence set in authentic contexts of language use whose goal is to negotiate intended meanings) through (re)constructing and inventing meaning, very often invisible in the act of communication. Consequently, under the premise of symbolic competence in action, the role of language is to name, categorise, order and classify reality (reference to Sapir/Whorf and Lakoff), perform speech acts and engage in communicative strategies (reference to Austin and Searle), construct social reality, (re)produce ideas and build cultures and identities through discourse (reference to Bourdieu and Foucault) (Kramsch, 2015). Developing linguistic performance involves acquiring symbolic mentality, rather than acquiring a certain mode of cross-cultural communication. Like Byram (1997) or Risager (2007), Kramsch (2011) extends the notion of communication beyond the exchange of information. However, unlike the two researchers, for whom communication is about either interaction with other people (Byram) or constructing meaning through interactive experience (Risager), Kramsch (2011) defines communication as reading people, events and situations, or even shaping the context in which communication takes place. From the perspective of ecological theory, the focus is on the meaning (not the code) of language, which is mediated, constructed, negotiated, recursive, emergent, unpredictable, reflexive, multidimensional and subjective. Thus, an ecological position of linguistic performance based on complexity theory assumes relativity of self and other (i.e. communication goes beyond transmitting information), the existence of timescales (i.e. meaning expressed through language is unpredictable and operates on multiple timescales), the emerging nature of symbolic competence (i.e. symbolic competence develops in a non-linear and unpredictable way), the unfinalisability of meaning (i.e. culture and meaning are not bounded by territory, but are defined by the communicative practices of people using language; there is no bounded interaction, which suggests a transnational approach to language), the existence of fractals (i.e. communication reveals the nature of social relations). Consequently, symbolic competence understood as communication requires language users to mediate between various language codes (i.e. symbolic systems) and their spatial and temporal aspects. 
Matsuo (2014) approaches linguistic performance from a dialogic perspective, which views it as "speech communication in dialogue" (Matsuo, 2014, p. 4). Rejecting the functionalists' communicative approach to language, Matsuo (2014) discards the native speaker as a role model, which is similar to Kramsch's (1993) position. Consequently, accepting Bakhtin's dialogic theory entails substituting the stable, solid, monologic, static, unitary and settled as the basis of the dialogue with the fluid, dynamic, constructivist, negotiated, infinite, collective, provisional, developmental and holistic.

\section{Towards a unified model of language-mediated IC}

The role of language is far from uniform and a number of tensions between the approaches reviewed above can be observed. Dichotomies between, for instance, biology and culture, representation and action, language and cognition, perceptual and linguistic symbols or encyclopedic and knowledge dominate contemporary perspectives upon the position of language in developing IC. While the emerging kaleidoscope of definitions and interpretations provides intriguing evidence for the evolution of the field, at its current point of development, where language is recognised as a unique affordance for meaning and identity construction, IC research should concentrate on unifying the existing approaches in a manner that is both consistent with the aims of language-mediated intercultural communication and based on theoretical advancements in disciplines whose goal is to construct bridges between language, culture and cognition.

Developing a consistent approach to language requires the phenomenon to be explained with reference to a common denominator. In other words, regardless of which facets of language we choose to concentrate on - whether the language faculty, the language system, linguistic competence or linguistic performance - the same underlying framework should be evoked. Moreover, as stated above, this unifying principle needs to be coherent with the overall aim of linguisticallymediated intercultural communication, which is meaning construction resulting in the qualitative and quantitative development of cognitive structures (Liu \& Zhang, 2014, p. 138). Thus, in order to discover a lens through which perspectives on language could be united within IC research and practice, we first turn to the notion of cognition and its possible links to the language faculty.

\section{The language faculty}

Langlotz (2015, p. 44) provides an overview of recent interpretations of cognition, which he broadly defines as "part of an individual cogniser, who interacts with the world of experience by means of his or her bodily capacities". The world of experience, in turn, encompasses both physical and socio-cultural properties of the cogniser's environment.

Depending on which, if any, aspects of the above-defined cognition interact, one can talk about autonomous, embodied, or situated/embedded cognition. Along this continuum, human mental capacities can be described as either independent or coupled with the body and/or the socio-cultural milieu. Moreover, cognition can be viewed as more or less dynamic, with theories of enactivism and distributed cognition concentrating on the human ability to incorporate the socio-cultural context into thinking and problem-solving processes. Consequently, cognition can rightly be interpreted not only as a repository of mental representations and cognitive processes that allow humans to capture the world of experience, but also as the ability to speak about those experiences, solve problems and undertake situationally-relevant action. Cognition is therefore a complex system, oscillating between biology and culture, an individual and a community, reflection and action, and its manifestations are context-induced.

The growing conviction that cognition is extended rather than encapsulated, and mediated instead of given, has evidently impacted upon the notion of the language faculty, which is now rarely viewed as an independent mental module (but see Fitch, Hauser, \& Chomsky, 2005). Instead, cognitive linguists advocate the embodiment of the human mind. For Lakoff and Johnson (1980), 
for instance, the language faculty is intertwined with other cognitive abilities and processes, including not only the classic ones, e.g. memory, categorisation or gestalt, but also human sensorimotor capacities, grounded in the enacted world of experience. Moreover, as Krzeszowski (1993) argues, embodied cognition is permeated by an axiological dimension and hence, a plus-minus parameter should be added to a number of mental structures and operations. Croft (2009, pp. 397-398) further extends the language faculty and argues that "grammatical structures and processes in the mind are instances of general social cognitive abilities", such as joint action, coordination and convention. Much in the same vein, Sinha (2009) acknowledges the role of culture in shaping the capacity for language, which is thus a cognitive-behavioural relationship, with language mediating both cultural reproduction and individual cognition. Consequently, the language faculty is not an innate language acquisition device but a generalised symbolic capacity built upon uniquely human cognitive skills of reading intentions and interacting with others socially (Tomasello, 2003). Likewise, Newby (2011, p. 18) argues that "what is innate in a child at birth is not only what Chomsky termed a language acquisition device but an experience acquisition device", and Christiansen and Chater (2015) urge that "it is time to return to viewing language as a cultural, and not a biological, phenomenon", which has, nevertheless, been formed by the cognitive properties of the human brain. Finally, Evans (2016) states that although the language faculty is not a separate module of the mind and language is in a symbiotic relationship with the conceptual system, i.e. "[language] has evolved and is designed to exploit [...] non-linguistic representations for purposes of linguistically mediated communication", it has simultaneously evolved a grammatical capacity, or "a means of words-to-words symbolic reference", which is a uniquely human trait.

All in all, the notion of the language faculty seems to be disappearing from linguistic discourse, replaced with narrower, or less epiphenomenal, concepts, i.e. symbolic and grammatical capacities. This shift, however, entails that a relationship between semiotic and grammatical abilities should be established. In other words, it needs to be decided if, or to what extent, linguistic symbols are exceptional within the human conceptual system.

\section{Conceptual and linguistic systems}

Firstly, Barsalou (1999) argues for two categories of symbols that constitute the basis of human knowledge - perceptual and linguistic - but gives special prominence to the former category. Perceptual symbols are schematic memories derived from sense perception, proprioception and subjective experience. If our experience of a given perceptual component becomes enriched, related perceptual symbols are integrated into a kind of a category, i.e. a simulator. Once established, simulators, analogously to mental schemata or frames, can produce an indefinite number of simulations, which are partial reenactments of a given concept. Consequently, a concept, or a competence, is "the ability to simulate a kind of thing perceptually" (Barsalou, 1999, p. 604) in order to "produce specialised category representations that support goal pursuit in the current setting" (Barsalou, 2009 , p. 244). Thus, simulators encompass patterns detected by individual cognition interacting with its socio-physical environment. In other words, perceptually-based categories are extended and situated to represent perspectival and intersubjective experience. This complex conceptual system, including simulators, simulations and situated conceptualisations, is then fit to account for thought in its various forms - from reflection, through interaction, to problem-solving. Linguistic symbols, in turn, are viewed as word forms generated by the language system - a distributional semantic model (Barsalou, Santos, Simmons, \& Wilson, 2008). Although conceptual and linguistic systems are closely intertwined, the latter is defined as a mere tool for indexing and controlling thought, with little role in constituting its content. Conversely, the Words as Social Tools (WAT) theory (Borghi \& Binkofski, 2014) proposes that linguistic experience is collected and schematised in simulators in the form of linguistic representations, i.e. acoustic properties, labels, explanations or inner speech, closely related to perceptual symbols via introspection. Finally, Evans (2016) argues for parametric concepts or "a species of concept that arose as a consequence of the emer- 
gence of language" to encode schematic representations typically associated with grammatical or function words. Since parametric concepts are characterised by highly attenuated content, which, according to Evans, is qualitatively different from the rich, multimodal structure of categories populating the conceptual system, they require a different form of explanation. Thus, for instance, in the noun phrase $a d o g$, the article refers to the sign $d o g$ rather than the conceptual system. An alternative view upon schematic content is postulated by Langacker (2008, p. 538), who describes grammatical concepts with reference to basic mental operations and socio-cognitive archetypes. Consequently, the meaning of the English possessive is inferred as "the conceptual operation of invoking a reference point to mentally access a target", which inheres in the archetypal concepts of ownership, kinship and part-whole and the schematic meaning of the is that of mental contact.

All in all, the link between the conceptual and linguistic systems of human cognition is best captured as a continuum. While, in accordance with the socio-cognitive nature of thought, language undoubtedly rests on the symbolic capacity developed from basic cognitive skills, relations between linguistic and perceptual simulators can range from symbiotic and perception-dominated to symbiotic and language-dominated. Acknowledging the fact that linguistic memories are grounded in the sensory modalities, distributed across brain regions, entangled in experience, dependent on culture and that therefore, as Sinha (2009, p. 300) argues, signs are both "cognitive tools, and constitutive of specifically human cultural ecologies", we adopt a unified approach to simulators. In other words, assuming mutual interpenetration of cognition, communication and action, we opt for "perceptual, motor, affective, introspective, social, linguistic and other information" (Lynott \& Connell, 2010, p. 80) to be all collected in a concept and available for inferencing. Among possible inferences supported by frame-like, situated simulators, schematic simulations are seen as special "attractors within human self-organising systems" (Gibbs, 2005, p. 115) due to their (near) universal or "preponderant" (Langacker, 2008, p. 20) nature.

\section{Schematic concepts}

Schematic simulators include image schemas, such as container, path or force (Johnson, 1987), mimetic schemas, e.g. grasping or holding (Zlatev, 2005), preconceptual preaxiological schemas (preschemas), for instance the axiologically-loaded in-out relation, or parametric (grammatical) concepts. While the exact nature of schematic categories is debatable, oscillating between preconceptual, prelinguistic and linguistic (see Hampe \& Grady, 2005 for a discussion), it can be assumed, in accordance with the unified approach described above, that schematic conceptualisations are fundamental to multifaceted simulators and can arise along each and any of its dimensions, including sensorimotor, affective, social or linguistic aspects of experience.

The symbolic capacity, built upon the socio-cognitive skills of finding patterns and reading intentions, which underlies language may be uniquely related to the schematic capabilities of the human mind. Thus, simulators, simulations and situated conceptualisations which constitute the conceptual system are closely intertwined with language on two counts. Firstly, the experience of language captured within multimodal and multilayered frames is an essential aspect of the content of human thought. Secondly, linguistic forms are coupled with simulations, or conceptualisations, to form symbolic units. Obviously, due to the multifaceted nature of simulators, a number of qualitatively different inferences are available as meaning potentials. Therefore, "conventional constraints play a vital role in stabilising language usage within a speech community. [...] The outcome of these constraints will function as default construals" (Croft \& Cruse, 2004, pp. 103-104), which are typical conceptualisations, or sets of inferences, crucially dependent on the frequency parameter. In fact, Barsalou et al. (2008, p. 249) argue that "statistical distributions of linguistic forms represent knowledge" and may be sufficient for adequate performance.

The main problem that the unified approach has with this proposal is the fact that it does not acknowledge the role of language experience in the emergence of linguistic associations. In other words, it claims that certain constellations of linguistic units arise as inferences since they 
have become salient, rather than merely frequent, in the experience of the conceptualiser. When acquiring language within a particular community of practice, "language users learn to associate default-construals with the patterned arrangement of [...] linguistic actions and cues" (Langlotz, 2015 , p. 255) and store them in underlying simulators for later retrieval. Thus, linguistic inferences are never merely associations of forms; instead, they are always, at least partly, coupled with the conceptual system through the underlying linguistic experience.

\section{Linguistic competence}

The language system is a structured inventory of conventional symbolic units, or constructions, arising out of interaction (Langacker, 2008; Tomasello, 2003). It is "a system of signs resting upon the conceptual system" (Kecskes, 2014, p. 81), which is both individual and shared, near-universal and culture-specific, linguistic and perceptual, detailed and schematic. As a result, linguistic competence can no longer be viewed as the possession of a formal grammar of semantically empty rules; instead it "involves the mastery of routine formulas, fixed and semi-fixed expressions, idioms, and frozen collocations" (Tomasello, 2003, p. 101), or the memory of salient constructions. Thus, in conventional situations, speakers "tend to do more remembering than putting together" (Kecskes, 2014, p. 108), they rely more on knowledge transfer than meaning creation and reproduce rather than transform language. Still, this tendency does not preclude the possibility that meaning construction in context combines the situated interactional negotiation with the discursive knowledge assembled in underlying simulators (Langlotz, 2015). Therefore, an essential element of linguistic competence is the ability to shift between fully idiomatic and fully idiosyncratic simulations, or to depart from the epistemic scaffolding and mediate the incongruities in the symbolic environment resulting from an unconventional manipulation of the cognitive setting. Frequently, reconciling the common ground requires that inferences be construed in a subjective (attenuated) rather than objective (detailed) manner, or as Sperber (1996) argues, that the formation of mental representations should occur through repeating and refining a common story. For instance, the English expression "digging one's own grave" was, according to Ritchie (2004), first rendered as a detailed narrative, evoking intense images related to actions, perceptions and emotions. The tragic implication of death was gradually foregrounded and strengthened through repeated use. Consequently, the meaning potential of the phrase has been subjectified, or attenuated, and the expression is now conventionally understood through only one of its possible implicatures. Since communicative situations depend heavily on conventionalised construals, the ability to convey and interpret schematised simulators seems an essential aspect of linguistic competence.

\section{Linguistic performance}

The final facet of language is the notion of performance, which, in the approach based on the concept of extended and mediated cognition, is closely related to the construct of linguistic knowledge. In other words, since context is integrated with the system and interpersonal, socio-cultural situations become an aspect of meaning, collective performance of language by communities of practice is an integral part of language. The ability to use linguistic constructions is indeed the function of a simulator, which is thus a set of strategies for action rather than a stable code, and a situated conceptualisation, or a multimodal simulation supporting a particular interaction with a category instance, is an example par excellence of how mental representations can be integrated with actions. Finally, language use is a fundamental aspect of language knowledge, or the linguistic ability of simulators, since, as already argued above, the linguistic input has a paramount impact on the conceptual system on two counts. Firstly, language experience shapes a number of mental representations and can thus be reenacted as linguistic simulations and secondly, language forms index and coordinate concepts, thus providing access to non-linguistic, e.g. sensorimotor or affective, parts of simulators. 
Language is thus a system of conventionalised constructions, whose meanings are rendered as conceptualisations negotiated between the conceptual system and the context of language use. Built on the socio-cognitive foundation, reconciling the biological and the cultural, the proposed definition of language derives from human symbolic capacities and rests on (near) universal schematic simulators. An essential part of the language system is constituted by formulaic expressions, characterised by attenuated conceptual content, salient within a particular community of practice. Since various communities may have conventionalised different simulations, an important part of linguistic competence is the ability to imply and infer schematic meanings.

\section{Language(s) in language-mediated IC}

Developing linguistically-mediated IC means that interlocutors become members of at least two communities of practice which are delineated by their first and foreign language. The latter is typically English used as a lingua franca (Kecskes, 2014). Language, embedded within the socio-cognitive context described above, is bound to respond to the conditions of the communicative setting. In other words, the systems, i.e. both a relatively stable L1 and an emerging ELF, need to co-adapt, which may in turn lead to self-organisation - the emergence of a more complex structure (Larsen-Freeman \& Cameron, 2008). This new pattern may well mean that certain attractor states become more, and others less, prominent and consequently, particular ends of the semantic-pragmatic, encapsulated-enactive, declarative-procedural, denotationalconnotational continua, proposed above, become more valid. Indeed, insights from second language acquisition, studies in English as an international language and intercultural pragmatics point to a particular skewing of the key concepts pertaining to language, which reinforces the unified sociocognitive approach to IC proposed above.

With reference to the notion of the language faculty, the symbolic capacity is both consistent with Kramsch's (2011) notion of symbolic competence and tightened by Newby's (2011, p. 19) idea of schematic competence. Elaborating on Skehan's (1998, p. 75) proposal that "the L2 learner has considerably greater cognitive abilities and schematic knowledge than the first language learner", Newby argues for a special, possibly universal, status of schematic knowledge, which results in and from a mode of perceiving events or utterances shared by a particular speech community. Thus, schematic constructs are largely conventional. Much in the same vein, Kecsces (2014, p. 161) suggests that a possible common ground between members of different L1 communities interacting through ELF is "the generalised knowledge of the language system", or systems. Importantly, the role of schematic, often grammatical, meanings within the symbolic capacity of ELF users is strengthened by the way in which the language of /for intercultural communication is acquired.

The way in which simulators are developed bears upon the quality of the conceptual system. Consequently, concepts formed on the basis of classroom experience, with a limited sociocultural context and a dominant role of language-mediated instruction, are bound to differ from those acquired through multidimensional social practice. Likewise, Kecskes (2014, p. 140) highlights the fact that in second language learning and bilingual experience, the first phase of development is dominated by an interaction of L2 and L1 lexical equivalents on the linguistic level, which "relies on linguistic rather than conceptual knowledge".

According to Borghi and Binkofski (2014), knowledge structures acquired through linguistic experience are likely to be more abstract, i.e. schematic, than those developed in a fully-fledged sociocultural milieu. Thus, ELF-related simulators, developed primarily through classroom experience, emerge as relatively more attenuated than if they were developed through socialisation. Moreover, as Kecskes (2014, p. 102) points out, a significant part of ELF-related knowledge "may originate through studying the linguistic code", including lexicalised and grammaticalised meanings, which strengthens the schematic competence of the students.

The importance of schematic simulators is also highlighted in the language knowledge of multilinguals. For instance, Cook (1991, p. 112) introduces the notion of multicompetence or "the 
compound state of mind with two grammars", which is a kind of supersystem characteristic of multiple language users' knowledge. The system is flexible, composed of "dynamic constellations of resources the shapes of which are emergent from interaction between internal architectures and cognitive processes on the one hand and social experiences on the other" (Hall, Cheng, \& Carlson, 2006, p. 229). These collections of semiotic resources are not only largely conventionalised but are also, as Bates (2003, p. 243) argues, species-specific means "to serve the many complex goals of human society and culture". Hence, according to Ford, Fox, \& Thompson (2014, p. 122), a supersystem is not a set of abstract rules but "a minimally sorted and organised set of memories of what people have heard and repeated over a lifetime of language use, a set of forms, patterns, and practices that have arisen to serve the most recurrent functions that speakers find need to fulfill". Multicompetence emerges from both intra and interpersonal experience and thus encompasses both mental and social realities as well as extra-linguistic variables.

The language system of ELF users participating in intercultural communication is likely to be akin to the supersystem described above, with the socio-cognitive interface scaffolded by means of "minimally sorted", schematic simulators. As a result, the conceptual system, or conceptual systems (Larsen-Freeman \& Cameron, 2008), of ELF users are populated by constellations of symbolic resources of various, and possibly competing, degrees of salience. On the one hand, there are bundles of conventional inferences drawn from L1-based simulators, and on the other there are schematic simulations underlying L2-related knowledge. Additionally, there are inferences salient to an individual, i.e. based on their unique experiences. Thus, in intercultural communication, prominent meanings have to be constantly negotiated and mediated in order to build an unbiased common ground. To reach this aim, the language supersystem has to be appropriately integrated with language use.

As Widdowson $(1998$, p. 8) says, context "is no longer apart from language but a part of it". Thus, as signalled above, schematic inferences need to become an integral part of language use in order to reinforce the "natural" predisposition of multiple language users to form schematic simulations. However, the main objective of linguistically-mediated intercultural communication is not just cognitive but above all axiological, in that quantitative changes in one's symbolic environment should be simultaneously qualitative. Therefore, we propose preconceptual preaxiological schemas (preschemas) as the ultimate common ground upon which intercultural communication should be constructed.

\section{Conclusion}

Adopting a unified socio-cognitive perspective on language is vital in order to foster linguisticallymediated meaning construction in intercultural communication in a way that both enriches the conceptual system(s) of the interlocutors and prevents stereotyping. The proposal developed in this article, which overcomes a number of inconsistencies related to the role of language in enhancing intercultural communication, is a possible means towards this end. Its undeniable appeal is a search for interfaces, or third spaces, between nature and nurture, system and context, languacognition and languaculture, or first and second language. The preschema, or the ultimate third space, may thus turn out to be a valid concept in linguistically-mediated intercultural communication.

Consequently, despite the announced importance of the language faculty, the linguistic system, linguistic competence and linguistic performance, the intercultural paradigm does not specify these concepts in a motivated way, which leads to unjustified dichotomies. Cognitive linguistics, with its focus on the interplay between the social and the cognitive, synthesises these notions, bringing balance to the previously unstable domain of intercultural competence. 
Towards a unified, socio-cognitive approach to language-mediated intercultural competence

\section{References}

Barsalou, L. W. (1999). Perceptual symbol systems. Behavioral and Brain Sciences, 22(4), 577-660. https : //doi.org/10.1017/S0140525X99002149

Barsalou, L. W. (2009). Simulation, situated conceptualization, and prediction. Philosophical Transactions of the Royal Society of London: Biological Sciences, 364(1521), 128-289. https://doi.org/10.1098/ rstb.2008.0319

Barsalou, L. W., Santos, A., Simmons, W. K., \& Wilson, C. D. (2008). Language and simulation in conceptual processing. In M. De Vega, A. M. Glenberg, \& A. C. Graesser (Eds.), Symbols, embodiment, and meaning (pp. 245-283). Oxford: Oxford University Press. https://doi.org/10.1093/acprof: oso/9780199217274.003.0013

Bates, E. (2003). Natura e cultura nel linguaggio. In R. D. Levi-Montalcini, R. Baltimore, R. Dulbecco, \& F. Jacob (Eds.), Frontiere della biologia: Il cervello di Homo sapiens (pp. 241-265). Rome: Istituto della Enciclopedia Italiana fondata da Giovanni Trecanni S.p.A.

Bennett, M. J. (1997). How not be a fluent fool. In A. E. Fantini (Ed.), New ways in teaching culture (pp. 16-21). Alexandria, VA: TESOL.

Borghi, A. M., \& Binkofski, F. (2014). Words as social tools: An embodied view on abstract concepts. Berlin: Springer. https://doi.org/10.1007/978-1-4614-9539-0

Byram, M. (1997). Teaching and assessing intercultural communicative competence. Clevedon: Multilingual Matters.

Byram, M. (2006). Language teaching for intercultural citizenship: The European situation. Paper presented at the NZALT conference, University of Auckland.

Byram, M. (2012). The Eric Hawkins lecture: Language awareness and (critical) cultural awareness relationships, comparisons and contrasts. Language Awareness, 21(1-2), 5-13. https://doi.org/10. $1080 / 09658416.2011 .639887$

Christiansen, M., \& Chater, N. (2015). The language faculty that wasn't: A usage-based account of natural language recursion. Frontiers in Psychology, 6. https://doi.org/10.3389/fpsyg. 2015.01182

Cook, V. (1991). Second language learning and language teaching. London: Edward Arnold.

Croft, W. (2009). Towards a social cognitive linguistics. In V. Evans \& S. Pourcel (Eds.), New directions in cognitive linguistics (pp. 395-420). Amsterdam: John Benjamins Publishing Company. https: //doi.org/10.1515/COGL.2009.009

Croft, W., \& Cruse, D. A. (2004). Cognitive Linguistics. Cambridge: Cambridge University Press. https : //doi.org/10.1017/CB09780511803864

Deignan, A. (2005). Metaphor and Corpus Linguistics. Amsterdam: John Benjamins Publishing Company. https://doi.org/10.1075/celcr.6

Evans, V. (2013). Metaphor, lexical concepts, and figurative meaning construction. Journal of Cognitive Semiotics, 5(1-2), 73-107.

Evans, V. (2016). Design features for linguistically-mediated meaning construction: The relative roles of the linguistic and conceptual systems in subserving the ideational function of language. https: //doi.org/10.3389/fpsyg.2016.00156

Fantini, A. E. (2010). Language: An essential component of intercultural communicative competence. In J. Jackson (Ed.), Handbook on intercultural communication (pp. 263-278). Oxon: Routledge.

Fitch, W. T., Hauser, M. D., \& Chomsky, N. (2005). The evolution of the language faculty: Clarifications and implications. Cognition, 97(2), 179-210. https://doi.org/10.1016/j.cognition.2005.02.005

Ford, C., Fox, B., \& Thompson, S. (2014). Social interaction and grammar. In M. Tomasello (Ed.), The new psychology of language (pp. 119-144). Hove: Psychology Press.

Gibbs, R. W. Jr. (2005). The psychological status of image schemas. In B. Hampe (Ed.), From perception to meaning: Image schemas in cognitive linguistics (pp. 113-135). Berlin: Mouton de Gruyter. https: //doi.org/10.1515/9783110197532.2.113

Hall, J. K., Cheng, A., \& Carlson, M. (2006). Reconceptualizing multicompetence as a theory of language knowledge. Applied Linguistics, 27(2), 220-240. https://doi.org/10.1093/applin/aml013

Hampe, B., \& Grady, J. E. (2005). From perception to meaning: Image schemas in cognitive linguistics. Berlin: Mouton de Gruyter. https://doi.org/10.1515/9783110197532

Johnson, M. (1987). The body in the mind: The bodily basis of meaning, imagination, and reason. Chicago: The University of Chicago Press.

Kecskes, I. (2014). Intercultural pragmatics. Oxford: Oxford University Press. 
Kramsch, C. (1993). Context and culture in language teaching. Oxford: Oxford University Press.

Kramsch, C. (2011). The symbolic dimensions of the intercultural. Language Teaching, 44(3), 354-367. https://doi .org/10.1017/S0261444810000431

Kramsch, C. (2015). What is symbolic competence and what can we do with it? Retrieved July 1, 2018, from http://blc.berkeley.edu/wp-content/uploads/2015/08/kramschSC.pdf

Krzeszowski, T. (1993). The axiological parameter in preconceptual image schemata. In R. A. Geiger \& B. Rudzka-Ostyn (Eds.), Conceptualizations and mental processing in language (pp. 307-330). Berlin: Mouton de Gruyter. https://doi.org/10.1515/9783110857108.307

Lakoff, G., \& Johnson, M. (1980). The metaphorical structure of the human conceptual system. Cognitive Science, 4(2), 195-208. https://doi.org/10.1207/s15516709cog0402_4

Langacker, R. W. (2008). Cognitive grammar: A basic introduction. Oxford: Oxford University Press. https://doi.org/10.1093/acprof : oso/9780195331967.001.0001

Langlotz, A. (2015). Creating social orientation through language. A socio-cognitive theory of situated social meaning. Amsterdam: John Benjamins Publishing. https://doi.org/10.1075/celcr.17

Larsen-Freeman, D., \& Cameron, L. (2008). Complex systems and applied linguistics. Oxford: Oxford University Press.

Liu, L., \& Zhang, Y. (2014). The application of constructivism to the teaching of intercultural communication. English Language Teaching, 7(5), 136-141. https://doi.org/10.5539/elt.v7n5p136

Lynott, D., \& Connell, L. (2010). Embodied conceptual cognition. Frontiers in Psychology, 1. https: //doi.org/10.3389/fpsyg.2010.00212

Matsuo, C. (2014). A dialogic critique of Michael Byram's intercultural communicative competence model: Proposal for a dialogic pedagogy. Retrieved July 1, 2018, from http://www.academia.edu/14378676/A_Dialogic_Critique_of_Michael_Byrams_Intercultural_ Communicative_Competence_Model_Proposal_for_a_Dialogic_Pedagogy

Newby, D. (2011). Competence and in learning and teaching: Theories and practices. In Selected Papers from the 19th ISTAL. Retrieved July 1, 2017, from http://www.enl.auth.gr/symposium19/ 19thpapers/002_Newby.pdf)

Risager, K. (2004). A social and cultural view of language. In H. L. Hansen (Ed.), Disciplines and interdisciplinarity in foreign language studies (pp. 21-34). Copenhagen: Museum Tusculanum Press.

Risager, K. (2006). Language and culture: Global flows and local complexity. Clevedon: Multilingual Matters.

Risager, K. (2007). Language and culture pedagogy: From a national to a transnational paradigm. Clevedon: Multilingual Matters.

Ritchie, D. (2004). Lost in "conceptual space": Metaphors of conceptual integration. Metaphor and Symbol, 19(1), 31-50. https://doi.org/10.1207/S15327868MS1901_2

Sinha, C. (2009). Language as a biocultural niche and social institution. In V. Evans, \& S. Pourcel (Eds.), New directions in cognitive linguistics (pp. 289-310). Amsterdam: John Benjamins Publishing. https://doi.org/10.1075/hcp.24.20sin

Skehan, P. (1998). A cognitive approach to language learning. Oxford: Oxford University Press.

Sperber, D. (1996). Explaining culture: A naturalistic approach. Oxford: Blackwell Publishing.

Strugielska, A., \& Piątkowska, K. (2017). A plea for a socio-cognitive perspective on the language-culturecognition nexus in educational approaches to ICC. Review of Cognitive Linguistics, 15(1), $224-252$. https://doi.org/10.1075/rcl.15.1.09str

Talmy, L. (2000). Toward a cognitive semantics. Cambridge, MA: MIT Press.

Tomasello, M. (2003). Constructing a language: A usage-based theory of language acquisition. Cambridge, MA: Harvard University Press.

Widdowson, H. G. (1998). Context, community and authentic language. TESOL Quarterly, 32(4), 705716. https://doi.org/10.2307/3588001

Zinken, J. (2007). Discourse metaphors: The link between figurative language and habitual analogies. Cognitive Linguistics, 18(3), 443-464. https://doi.org/10.1515/COG.2007.024

Zlatev, J. (2005). What's in a schema? Bodily mimesis and the grounding of language. In B. Hampe (Ed.), From perception to meaning: Image schemas in cognitive linguistics (pp. 313-343). Berlin: Mouton de Gruyter. https://doi.org/10.1515/9783110197532.4.313 
This work was financed by the Polish Ministry of Science and Higher Education.

The authors declare that they have no competing interests.

The authors' contribution was as follows: concept of the study: Ariadna Strugielska (50\%), Katarzyna Piątkowska (50\%); data analyses: Ariadna Strugielska (50\%), Katarzyna Piątkowska (50\%); the writing: Ariadna Strugielska (50\%), Katarzyna Piątkowska (50\%).

This is an Open Access article distributed under the terms of the Creative Commons Attribution 3.0 PL License (http://creativecommons.org/licenses/by/3.0/pl/), which permits redistribution, commercial and noncommercial, provided that the article is properly cited.

(C) The Authors 2018

Publisher: Institute of Slavic Studies, Polish Academy of Sciences, University of Silesia \& The Slavic Foundation 